\title{
The Coronavirus Disease-19 Infection and the Oral Mucosa
}

\author{
Pier Carmine Passarelli ${ }^{1}$, Luigi Santacroce ${ }^{2 *}$, Antonio D’Addona ${ }^{3}$, Franklin Garcia-Godoy ${ }^{4,5}$ \\ ${ }^{1}$ Department of Head and Neck, Oral Surgery and Implantology Unit, Master Coordinator, Institute of Clinical Dentistry, Università \\ Cattolica del Sacro Cuore, Fondazione Policlinico Universitario Gemelli, Rome, Italy; ${ }^{2}$ lonian Department, Microbiology and \\ Virology Lab, University Hospital of Bari, Bari, Italy; ${ }^{3}$ Department of Head and Neck, Oral Surgery and Implantology Unit, \\ Institute of Clinical Dentistry, Università Cattolica del Sacro Cuore, Fondazione Policlinico Universitario Gemelli, Rome, Italy; \\ ${ }^{4}$ Bioscience Research Center, College of Dentistry, University of Tennessee Health Science Center, Memphis, Tennessee, \\ USA; ${ }^{5}$ Senior Clinical Investigator, The Forsyth Center, Cambridge, Massachusetts, USA
}

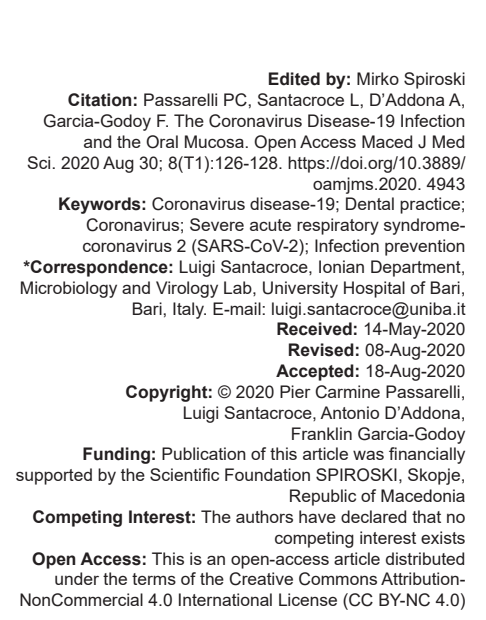

Abstract

BACKGROUND: The current coronavirus disease (COVID-19) pandemics induced a modification of daily life and clinical practice. Health care workers, particularly dentists and dental hygienists, have been obliged to limit their activity and to establish new operative protocols.

AIM: We aimed to discuss an easy protocol for the prevention of cross-infections in dental settings.

METHODS: We revised literature data about COVID-19 and oral health to establish how to work safely with dental patients.

RESULTS AND CONCLUSION: A few papers are currently available about the effective prevention of COVID-19 during dental procedures. Most of the revised articles report a potential strong effectiveness of povidone-iodine and its safety for both patients and dental professionals.

\section{Introduction}

The novel coronavirus (CoV), officially named as severe acute respiratory syndrome (SARS)-CoV-2, is a newly discovered virus, responsible for the so-called CoV infectious disease (COVID)-19, an infection originating in the upper airways. COVID-19 infection occurs mainly by air droplets and after a considerable introduction of viruses particles in closed and poorly ventilated rooms, at close contact with the presumed positive person; also by contact with contaminated objects, where COVID-19 can survive for some hours [1], [2], [3].

Then, it is spread through direct or indirect contact with the oral, the nasal cavity and the eye mucous membranes. At this level, SARS-Cov2 seems to cause chemosensory dysfunction as ageusia and anosmia [2].

The most likely cause for transient hypogeusia and hyposmia in SARS-CoV2-infected patients is a direct contact and interaction of the virus with gustatory receptors or olfactory receptor cells [3]. The oral mucosa could be stimulated by speaking, coughing, and sneezing and viral particles have the ability to become aerosolized; they can stay in the air for 3 or more hours and may spread to contaminate multiple surfaces in the surrounding area [4]. As a consequence, the SARS-CoV-2 became able to interfere with both respiratory and oral environment, also determining temporary (and perhaps permanent) damages of central nervous system [5], [6].

Given the capability of the SARS-CoV-2 of surviving over surfaces for several hours, it is crucial to perform an appropriate disinfection of the oral mucosa before any intervention [7], [8]. Furthermore, arising evidences exist about the positive action of antiviral and anti-allergic drugs in the oral district that seems to be useful in ameliorating the inflammatory status and reducing potential infection transmission. However, at least 10 clinical trials have been started to evaluate the efficacy and potential side effects of other products, including the ones used for oral hygiene [7], [8], [9].

While studies on virucidal activity of povidoneiodine (PVP-I) have not yet been performed specifically on SARS-CoV-2, several in vitro studies demonstrated 
its effectiveness against multiple viruses including related CoVs; for example, Eggers et al. examined a diluted PVP-I (0.23\%) formulation against SARS-CoV-1, MERSCoV, and influenza A (H1N1) applied for $15 \mathrm{~s}$ and found $>99.99 \%$ reduction of viral titers [10]. Mouthwash/gargles for 1 min with a solution of PVP-I diluted 1:3 (for 7.5\% PVPI) or $1: 4$ (for $10 \%$ PVP-I) to achieve $<3 \%$ concentration is safe and may help to reduce the viral load and the potential aerosolization of SARS-CoV-2. It could be effective to reduce viral load from asymptomatic COVID19 patients, also providing a protective oropharyngeal hygiene measure for the health professionals. Moreover, as suggested by Sampson [11], oral hygiene should be improved during a COVID-19 infection aiming to reduce the bacterial load in the mouth and the risk of a bacterial superinfection. These easy-to-do, cost saving tips may be performed in any dental setting and effective to reduce the risk of severe infections [12], [13], [14]. Our suggestion is to maintain an extremely high level of oral hygiene to avoid any dental emergencies, therefore, patients should wash their teeth at least twice a day, floss daily, and use a PVP-I mouthwash thrice a day. This not only reduce the risk of dental emergencies but the oral viral load also and might, even if there is no evidence, reduce the risk of contaminating the surrounding environment [15], [16], [17].

By the way, based on the current literature, we can use local iodine-based products associated with systemic antiviral and anti-inflammatory drugs to avoid the infection spreading [18], [19], [20].

\section{Conclusion}

We must deepen our knowledge about SARS-CoV-2 biology and better understand the oral pathophysiology of COVID-19 to establish specific protocols to prevent its transmission and clinical consequences.

\section{References}

1. Santacroce L, Charitos IA, Del Prete R. COVID-19 in Italy: An overview from the first case to date. Electron J Gen Med. 2020;17:em235. https://doi.org/10.29333/ejgm/7926

2. Grasselli G, Zangrillo A, Zanella A, Antonelli M, Cabrini L, Castelli A, et al. Baseline Characteristics and Outcomes of 1591 Patients Ifected With SARS-CoV-2 Admitted to ICUs of the Lombardy Region, Italy. JAMA. 2020;323(16):1574-81. https:// doi.org/10.1001/jama.2020.5394

PMid:32250385

3. Baymakova M, Popov GT. SARS-CoV-2 infection: A review of part of the international experience. Bulg Med J. 2020;14(1):7-12.

4. Passarelli PC, Lopez MA, Bonaviri GN, Garcia-Godoy F, D'Addona A. Taste and smell as chemosensory dysfunction in
COVID-19 infection. Am J Dent. 2020;33(3):135-7.

PMid:32470238.

5. Dziedzic, A, Wojtyczka, R. The impact of coronavirus infectious disease 19 (COVID-19) on oral health. Oral Dis. 2020;1:1-4. https://doi.org/10.1111/odi.13359

PMid:32304276

6. Cazzolla AP, Lovero R, Lo Muzio L, Testa NF, Schirinzi AL, Palmieri G, et al. Taste and smell disorders in COVID-19 patients: Role of Interleukin-6. ACS Chem Neurosci. [published online ahead of print, 2020 Aug 4]. https://doi.org/10.1021/ acschemneuro.0c00447

PMid: 32786309

7. Verillaud B, Slama D, Ayache D, Herman P, Jourdaine C Hervé C, et al. Efficacy of local budesonide therapy in the management of persistent hyposmia in COVID-19 patients without signs of severity: A structured summary of a study protocol for a randomised controlled trial. Trials. 2020;21(1):666. https://doi.org/10.1186/s13063-020-04585-8 PMid:32690074

8. Li J, Zhang C, Wu Z, Wang G, Zhao H. The mechanism and clinical outcome of patients with corona virus disease 2019 whose nucleic acid test has changed from negative to positive, and the therapeutic efficacy of favipiravir: A structured summary of a study protocol for a randomised controlled trial. Trials. 2020;21(1):488. https://doi.org/10.1186/s13063-020-04430-y PMid:32503657

9. Ong SW, Tan YK, Chia PY, Lee TH, Ng OT, Wong MS, et al. Air, surface environmental, and personal protective equipment contamination by severe acute respiratory syndrome coronavirus 2 (SARS-CoV-2) from a symptomatic patient. JAMA. 2020;323(16):1610-2. https://doi.org/10.1001/jama.2020.3227 PMid:32129805

10. Eggers M, Koburger-Janssen T, Eickmann M, Zorn J. In vitro bactericidal and virucidal efficacy of povidone-iodine gargle/ mouthwash against respiratory and oral tract pathogens. Infect Dis Ther. 2018;7(2):249-59. https://doi.org/10.1007/ s40121-018-0200-7

PMid:29633177

11. Sampson V. Oral hygiene risk factor. Br Dent J. 2020;228:569. https://doi.org/10.1038/s41415-020-1545-3 PMid:32332938

12. DiSerio F, Lovero R, D'Agostino D, Nisi L, Miragliotta G, Contino R, et al. Evaluation of procalcitonin, Vitamin $\mathrm{D}$ and C-reactive protein levels in septic patients with positive emocoltures. Our preliminary experience. Acta Med Mediterr. 2016;32:1911-4. https://doi.org/10.19193/0393-6384_2016_6_182

13. Gugnani N, Gugnani S. Safety protocols for dental practices in the COVID-19 era. Evid Based Dent. 2020;21(2):56-7. https:// doi.org/10.1038/s41432-020-0094-6 PMid:32591659

14. Passarelli PC, Passarelli G, Charitos IA, Rella E, Santacroce L, D'Addona A. COVID-19 and oral diseases: How can we manage hospitalized and quarantined patients while reducing risks? Electron J Gen Med. 2020;17(6):em238. https://doi. org/10.29333/ejgm/7945

15. Sadeghi AM, Karimzadeh I, Lankarani KB, Banakar M. Pharmacotherapy for reducing saliva and droplet production in airborne procedures may help to decrease the COVID-19 transmission: A hypothesis. Med Hypotheses. 2020;144:109874. https://doi.org/10.1016/j.mehy.2020.109874 PMid:32535455

16. Passarelli PC, Rella E, Manicone PF, Garcia-Godoy F, D'Addona A. The impact of the COVID-19 infection in dentistry. Exp Biol Med (Maywood). 2020;245(11):940-4. https://doi. org/10.1177/1535370220928905 
PMid: 32436748

17. Alharbi A, Alharbi S, Alqaidi S. Guidelines for dental care provision during the COVID-19 pandemic. Saudi Dent J. 2020;32(4):181-6. https://doi.org/10.1016/j.sdentj.2020.04.001 PMid:32292260

18. Santacroce L, Bottalico L, Charitos IA. The Impact of COVID19 on Italy: A Lesson for the Future. Int J Occup Environ Med. 2020;11(3):151-2. https://doi.org/10.34172/ijoem.2020.1984 PMid:32225178
19. Santacroce L. Letter in response to the article "Enhancing immunity in viral infections, with special emphasis on COVID19: A review" (Jayawardena et al.). Diabetes Metab Syndr. 2020;14(5):927. https://doi.org/10.1016/j.dsx.2020.06.009 PMid:32585601

20. Charitos IA, Ballini A, Bottalico L, Cantore S, Passarelli PC, Inchingolo $F$, et al. Special features of SARS-Cov2 in daily practice. World J Clin Cases 2020;(in press). 